\title{
0 espaço da formação inicial do coordenador pedagógico
}

\author{
The initial formation space of the pedagogical coordinator \\ La formación inicial del coordinador pedagógico
}

\author{
Susana Soares Tozetto* \\ Priscila Gabriele da Luz Kailer**
}

\section{Resumo}

Analisar a formação inicial do coordenador pedagógico torna-se uma tarefa árdua quando se considera as contradições presentes no processo formativo e, consequentemente, no trabalho desse profissional. A conquista do escopo específico de trabalho do coordenador pedagógico, na escola, precisa estar atrelada a saberes de bases teóricas e práticas. Este artigo tem como objetivo analisar os saberes que compõem a formação inicial do coordenador pedagógico. Os relatos de oito coordenadoras pedagógicas, sujeitos desta pesquisa, coletados por meio de entrevista, deflagram uma formação que desvaloriza os conhecimentos práticos e uma atuação que desconsidera os conhecimentos teóricos. Assim, o entendimento errôneo da universidade como espaço exclusivamente teórico e da escola como peculiar às questões práticas manifesta-se nas falas dessas profissionais.

Palavras-chave: Coordenador pedagógico. Formação inicial. Saberes.

\section{Abstract}

Analyzing the initial training of the pedagogical coordinator becomes an arduous task when one considers the contradictions present in the formative process and, consequently, in the work of this professional. The achievement of the specific scope of work of the pedagogical coordinator at school must be linked to theoretical and practical knowledge. In this sense, this paper aims to analyze the knowledge that make up the initial training of the Pedagogical Coordinator. The reports of eight pedagogical coordinators, subjects of this research, collected through interviews, trigger a training that devalues the practical knowledge and an enactment that ignores theoretical knowledge. Thus, the erroneous understanding of the university as exclusively theoretical space and of the school as peculiar to the practical questions manifests itself in the speeches of these professionals.

Keywords: Pedagogical coordinator. Initial training. Knowledge.

Recebido em 08/10/2018 - Aprovado em 18/06/2019

http://dx.doi.org/10.5335/rep.v26i3.7262

Doutora em Educação Escolar pela Universidade Estadual Paulista Júlio de Mesquita Filho (Unesp). Docente Associada do Departamento de Educação e do Programa de Pós-Graduação em Educação da Universidade Estadual de Ponta Grossa (UEPG). Brasil. ORCID: http://orcid.org/OOOO60002616966667X. E-mail: tozettosusana@hotmail.com

** Mestre em Educação pela Universidade Estadual de Ponta Grossa (UEPG). Docente da rede municipal de Ponta Grossa e da Faculdade Arapoti (FATI). Brasil. ORCID: http://orcid.org/0000-0003-2490-4509. E-mail: kailer.priscila@yahoo. com.br 


\title{
Resumen
}

\begin{abstract}
Analizar la formación inicial del coordinador pedagógico se convierte en una tarea ardua al considerar las contradicciones presentes en el proceso formativo y, en consecuencia, en el trabajo de este profesional. El logro del alcance específico del trabajo del coordinador pedagógico en la escuela debe estar vinculado al conocimiento de bases teóricas y prácticas. Este artículo tiene como objetivo analizar los conocimientos que conforman la formación inicial del coordinador pedagógico. Los informes de ocho coordinadores pedagógicos, sujetos de esta investigación, recopilados a través de una entrevista, desencadenan una formación que devalúa el conocimiento práctico y una acción que ignora el conocimiento teórico. Así, el malentendido de la universidad como un espacio exclusivamente teórico y de la escuela como peculiar a los temas prácticos se manifiesta en los discursos de estos profesionales.
\end{abstract}

Palabras clave: Coordinador pedagógico. Formación inicial. Conocimiento.

\section{Introdução}

Os avanços e os retrocessos em relação à formação de professores são resultados de um conjunto de transformações históricas que afetam de maneira significativa a definição de políticas e as práticas pedagógicas que temos na atualidade. Nesse sentido, Nóvoa (1995) aponta que a formação de professores se encontra como elemento central das mudanças que ocorrem no sistema educativo. A atenção destinada à formação dos professores nos últimos anos advém da responsabilização dos profissionais da educação, conforme pressupostos das políticas neoliberais, que atribuem ao professor o sucesso ou o fracasso de seu trabalho (GIMENO SACRISTÁN, 1999). Da mesma forma, a formação fica fragilizada quando está arraigada ao significado de competências e de habilidades, propondo um novo sentido ao ensino (KUENZER, 2006).

Não cabe responsabilizar a formação dos profissionais da educação pelos problemas da educação, mas compreender a formação inicial como um espaço significativo, que, permeado por um contexto social, político, econômico e cultural, esforça-se em preparar esse profissional para exercer uma ação consciente e transformadora. Para tanto, faz-se necessário que essa ação esteja atrelada à realidade da escola e que contribua com a atuação do profissional da educação. Assim, a universidade, espaço de produção e legitimação dos saberes, precisa compreender aspectos centrais do trabalho dos profissionais que pretende formar.

O curso de Pedagogia no Brasil forma docentes para atuação nos anos iniciais do ensino fundamental, na educação infantil e, também, na área da gestão escolar, ou seja, os coordenadores pedagógicos. Cabe pontuar que, se a concepção do coordenador pedagógico e/ou professor, já no processo formativo, encontra-se fragmentada ou dispersa, isso tem consequência no desenvolvimento de seu traba- 
lho na escola. Nesse contexto, destacam-se as pesquisas de Gatti (2010), que têm apontado a fragilidade na formação inicial dos profissionais da educação. Assim, o presente artigo tem como objetivo analisar o processo formativo inicial do coordenador pedagógico que atua nos anos iniciais do ensino fundamental.

Ao considerar os contextos de atuação do coordenador pedagógico na escola e sua influência no trabalho dos professores, para esta pesquisa, delimitamos os coordenadores pedagógicos egressos do Curso de Pedagogia da Universidade Estadual de Ponta Grossa no ano de 2010 e que atuam nas escolas públicas municipais de Ponta Grossa, a fim de retratar de forma mais precisa a realidade desse contexto. Após contato com os 76 pedagogos, encontramos 6 egressos do referido curso que se encontram na coordenação pedagógica das escolas públicas municipais de Ponta Grossa.

Ressaltamos que as coordenadoras pedagógicas, em sua maioria, cursaram pós-graduação, o que retrata uma preocupação com o desenvolvimento profissional e que possibilita condições para níveis mais elevados da carreira docente. Do mesmo modo, cabe destacar o período expressivo de atuação na docência das coordenadoras pedagógicas: entre 11 e 13 anos em sala de aula.

As entrevistas foram gravadas com o consentimento dos sujeitos e transcritas de forma fidedigna, o que resultou em uma média de duas horas de duração. As entrevistas, com perguntas semiestruturadas, foram realizadas nos espaços das escolas em que as coordenadoras pedagógicas atuam, com exceção de uma profissional que preferiu fazer em sua residência. Para tanto, o termo de consentimento livre e esclarecido (TCLE) foi devidamente apreciado por todas as participantes da pesquisa, as quais serão citadas neste trabalho como: CP1, CP2, CP3, CP4, CP5 e CP6.

Para compreender os saberes que emergem da formação inicial, utilizamo-nos da análise de conteúdo de Bardin (1977, p. 33), que se caracteriza como "[...] um conjunto de técnicas de análise das comunicações". No entanto, não se trata de um instrumento simples, mas de uma análise rigorosa, marcada por diferentes formas e adaptável a um campo vasto de aplicação.

Diante disso, as entrevistas foram analisadas rigorosamente e agrupadas de acordo com uma estrutura interna, em categorias de análise. A categoria que analisamos no presente artigo foi denominada de formação inicial do coordenador pedagógico. Assim, consideramos importante iniciar a discussão contextualizando a pedagogia historicamente. 


\section{A pedagogia no Brasil}

A pedagogia possui sua gênese em um vínculo estreito com a educação, pois era entendida na Grécia como um modo de apreender ou de instituir o processo educacional. Nesse sentido, o conceito de pedagogia, desde a Grécia, delineou-se de maneira dualista, com uma concepção ora voltada para uma reflexão de ordem filosófica, ora compreendida em um sentido prático e empírico.

Para compreender o sentido filosófico destacado por Saviani (2008), é preciso considerar o contexto grego, que, sustentado pela supremacia da razão e pela redução da importância prática, colocava a transformação do mundo material como um objetivo secundário dos pensadores. Ao reconhecer o protagonismo do mundo real em detrimento do homem, os primeiros pensadores voltaram seus estudos a compreender o cosmo, visando à contemplação do universo, sem haver a preocupação em transformar a natureza ou desenvolver estudos que pudessem modificar as estruturas sociais e o sentido das ações humanas (VÁZQUEZ, 1968). Em decorrência desse entendimento, a pedagogia obtinha forte influência da filosofia, orientada pelos princípios e pelas ideias de maneira distante dos processos educativos.

A visão prática, apontada por Saviani (2008), estava intrínseca à formação realizada pela paidéia ${ }^{1}$, na qual se afirmava o aspecto metodológico, pautado pelo entendimento etimológico da palavra, como meio e caminho e, posteriormente, sendo incorporada à terminologia pedagogia. Assim, a terminologia "pedagogo", na Grécia, designava o escravo que acompanhava a criança até o professor. A crença da superioridade da atividade intelectual em relação ao trabalho prático demonstra-se na oposição entre uma atividade considerada elevada - atividade intelectual - e a outra servil e humilhante - trabalho prático (SAVIANI, 2008). O trabalho prático era tarefa designada aos escravos, por ser considerada indigna para os homens livres, atribuindo, então, a estes atividades filosóficas e políticas, pautadas pela ação contemplativa. Já no período medieval, havia forte influência da igreja e do cristianismo, o que se expressou em um modelo de paidéia cristianizada, ou seja, uma formação com abordagem hierárquica e ambígua.

$\mathrm{Na}$ busca de validar e reconhecer um conhecimento como científico, a ciência moderna, pautada pela concepção positivista, promove mudanças profundas e estabelece uma nova concepção de ciência. As características de cientificidade, como a questão da racionalidade e da veracidade, enfatizadas pela ciência moderna, não se assemelham aos métodos, aos objetivos e aos instrumentos para a área das ciências humanas, na qual a pedagogia está inserida. Entretanto, para garantir o 
estatuto científico, as ciências humanas adotam caraterísticas do rigor do método quantitativo pautado pela abordagem positivista. Com a rigorosidade matemática e a exigência de quantificação, não havia espaço no padrão moderno para as ciências humanas e, consequentemente, para a pedagogia, a psicologia e a sociologia. A rigorosidade matemática das ciências humanas implica uma nova abordagem do conhecimento e, consequentemente, uma exclusão da troca das ideias e da necessidade filosófica (BOURDIEU, 2008).

Diferente do paradigma greco-medieval voltado para a produção da ciência embasada nas leis da espiritualidade, a modernidade elabora um pensamento embasado nas leis matemáticas. Desse modo, as ciências naturais foram as primeiras a estabelecerem os critérios científicos de validação, sendo reconhecidas como as ciências exemplares.

O caráter do estudo das ciências humanas, tendo como foco a relação do homem com a realidade social, enquanto uma relação dinâmica, mutável e complexa, não permite ao pesquisador uma análise exclusivamente mensurável e observável dos fatos sociais. A compreensão da relação que ocorre entre os sujeitos não se realiza por meio de técnicas, a realidade e as influências culturais, históricas, econômicas e sociais tornam esse conhecimento muito mais complexo (ZAVAGLIA, 2008). Ao tratar da ciência, Zavaglia (2008) destaca que não há uma única forma de enquadrar a ciência e todo o conhecimento, produto da ciência, pois estão pautados por elementos sociais, culturais e políticos.

Nesse cenário, Plaisance e Vergnaud (1993) destacam a vulnerabilidade da pedagogia em relação às outras ciências, ao considerar que ela se mostra associada à formação de professores para atuar nos cursos primários. O dilema de compreender a pedagogia como ciência percorreu longos anos. A submissão da pedagogia, ora à sociologia, ora à psicologia, ora à filosofia, tornou-a independente de outros objetos, linguagens e métodos, o que resultou na falta de uma autonomia, reduzindo-a, conforme postula Saviani (2008), à mera aplicação dos resultados de outras ciências.

De acordo com Saviani (2008), o século XIX tendeu a generalizar o entendimento da pedagogia para designar a relação entre a elaboração consciente do ensino e o fazer sobre o processo educativo, desse modo, intitulava a relação entre os processos teórico e prático do ensino. Cabe considerar que o distanciamento entre os segmentos da teoria e da prática tornou-se uma questão evidente no processo de formação de professores, que, conforme Gatti (2010), permanece até os dias atuais.

Compete esclarecer que os desígnios da pedagogia, no Brasil, obtiveram distinção do modo como ela se delineou em outras partes do mundo. Enquanto em 
outros países a pedagogia firmou-se como parte estruturante das ciências da educação, sendo compreendida nos cursos de formação docente, no Brasil, embora não haja consenso, a nomenclatura "pedagogia" refere-se aos cursos de formação de professores dos anos iniciais do ensino fundamental e da educação infantil e de coordenadores pedagógicos. Pimenta (1999), Libâneo (2001) e Franco (2003) defendem a ideia da pedagogia como ciência da educação.

\section{Formação inicial do coordenador pedagógico}

Notamos que o século XX foi o palco de grandes transformações ${ }^{2}$ no cenário nacional e mundial, entrando em voga a supervalorização da educação como componente principal do progresso. A fim de adequar-se aos interesses mercantis e às novas exigências no trabalho, a universalização do ensino passa a ser uma necessidade do Estado. Com a supremacia da educação, a formação dos professores passou a ser tema importante no âmbito de reformas ${ }^{3}$, leis e projetos. Para Kuenzer (2006), a concepção positivista influenciou de maneira significativa o modelo de organização e de seleção dos conteúdos do processo formativo do século XX. Com isso, prevaleceu uma noção de ciência formalizada e fragmentada, na qual cada objeto corresponde a uma singularidade que, ao construir seu próprio campo, se desvincula das demais especificidades e perde seu vínculo com as relações sociais e produtivas.

No contexto da formação, o coordenador pedagógico não estava vinculado às funções inerentes do trabalho pedagógico. No início, seu viés ainda estava se referindo a um técnico ou especialista da educação (SAVIANI, 2008). O reflexo dessas funções na escola dá-se pelo viés de fiscalização e pelas incumbências de inspeção. Nesse sentido, ocorreram mudanças decorrentes das reformas com destaque para a implantação da Faculdade de Filosofia, Ciências e Letras, que surgiu, primeiramente, na Universidade de São Paulo. Somente em 1939, a terminologia "Pedagogia” ganhou espaço universitário e passou a fazer parte, juntamente a Didática, Filosofia, Ciências e Letras, de uma das sessões da Faculdade Nacional de Filosofia. Posteriormente, com a duração de quatro anos, os cursos de licenciatura, inclusive Pedagogia, seguiam o modelo conhecido como $3+1$, em que se destinavam os primeiros três anos para a formação dos bacharéis com os conhecimentos metodológicos e cognitivos, e o último ano para a formação da licenciatura com conhecimentos didáticos (SAVIANI, 2008). 
Nessa conjuntura, desde a década de 1970 até a de 1990, a organização do curso de Pedagogia não refletia um caráter escolar, muito menos de aprendizagem para docência. A organização fragmentada trazia um distanciamento entre a teoria e a prática, que não possibilitava ao estudante perceber qual era sua real função no âmbito da escola.

Aproximando-se, dessa forma, das funções cada vez mais técnicas e menos vinculadas às ações docentes e pedagógicas, a fala de uma coordenadora pedagógica entrevistada pontua sobre a dificuldade em reconhecer o trabalho do coordenador pedagógico na formação inicial:

No curso, eu não conseguia perceber o trabalho do coordenador pedagógico, eu não me reconhecia neste trabalho [...]. Inclusive nos primeiros meses como coordenadora eu me via voltando para a sala de aula (CP4).

O reconhecimento do saber específico do futuro profissional manifesta-se no processo de formação inicial. Desse modo, o trabalho que o coordenador pedagógico exerce na escola deveria estar atrelado à formação inicial, no entanto, a coordenadora CP4 relata que não se percebia na função e desejava retornar para a sala de aula. Assim, inferimos que o curso de Pedagogia lhe deu o direito de exercer a função de coordenadora pedagógica, mas não ofereceu fundamentação teórico-prática suficiente para tal.

Com isso, percebe-se que o pertencimento a um grupo profissional requer a apropriação de um conhecimento específico e sistematizado, que se realiza na formação do profissional nos espaços universitários.

Impulsionadas pelas ideias de progresso e pela necessidade de mão de obra, as décadas de 1960 e 1970 foram marcadas por uma expansão do sistema de ensino. A ampliação das escolas e, consequentemente, o aumento do número de vagas ofertadas trouxeram uma necessidade de formar professores em grande escala, sem, contudo, haver proporcional investimento na qualidade dessa oferta.

No contexto desse movimento questionador sobre qualidade da formação inicial do professor, o curso de Pedagogia apresentava uma profunda crise, que se manifestava sem perspectivas de melhoras, levando em consideração os novos componentes a serem instaurados no âmbito da formação: os institutos superiores de educação (IES) e as escolas normais superiores, na década de 1990. Tais espaços de formação do professor foram implementados pela Lei no 9.394/1996 (BRASIL, 1996), alicerçada pela concepção das políticas educacionais vigentes.

Cabe considerar que as reformas realizadas na década de 1990 tinham como intuito alterar a estrutura do ensino desde a educação infantil até o ensino supe- 
rior, destinando a educação como alternativa de superar a crise equacionada pelo modelo de produção capitalista. Com essa configuração, a Lei no 9.394/1996 (BRASIL, 1996) promoveu uma ampla modificação no ensino e, consequentemente, na formação do professor e do coordenador pedagógico.

No relato a seguir, a coordenadora pedagógica pontua sobre a importância do curso de Pedagogia no trabalho que realiza na escola:

Eu nunca tinha trabalhado em escola e foi lá que eu aprendi tudo. Não me acho diferente de uma pessoa que teve Magistério, eu não tive Magistério. Tudo que eu aprendi foi na Pedagogia como organização pedagógica, metodologia, planejamento. A base para o trabalho que realizo hoje, eu tive no curso. Quando eu cheguei na Prefeitura, eu não tive alguém para me orientar, eu não sabia nem preencher um livro de chamada, ninguém me ensinou e eu não tinha experiência em escola, eu aprendi lá no curso de Pedagogia, nos estágios e nas disciplinas (CP2).

Em virtude das políticas e do modelo de formação instaurados historicamente nos anos 1990 e 2000, Pabis (2014) destaca que o curso de Pedagogia permaneceu fragmentado. Cabe considerar as inúmeras intervenções da Associação Nacional pela Formação dos Profissionais da Educação (ANFOPE) e de outros movimentos dos professores, na tentativa de alterar o quadro de distinção entre a formação do professor e a do especialista. Após muita discussão, propôs-se que o curso de Pedagogia se fundamentasse nos três eixos de formação: pesquisador, gestor e professor. Pautados na concepção crítica de ensino e contrários ao modelo de fragmentação da formação do coordenador pedagógico, os movimentos dos professores tornaram-se importantes no processo de defesa da profissionalização do magistério. De uma formação inicial consistente teoricamente, permitiram-se condições para a formação do professor, com referência ao exercício em sala de aula, do gestor, como o responsável pela organização do trabalho pedagógico, e do pesquisador investigador, aquele que realiza a pesquisa educacional.

O relato a seguir pontua sobre a importância do conhecimento da teoria que se faz presente nas atividades realizadas pelo coordenador pedagógico:

Porque tem muito da teoria que você vai precisar. E você vê, plenamente, a pessoa que tem um certo descaso com algumas questões, às vezes é por não conhecer. Então, é necessário, por exemplo, para o preenchimento de uma ata, saber o que é direito da criança, o que você vai cobrar, porque é uma questão familiar. Tem situações que você vai encaminhar para outros órgãos, mas não é você que vai tentar resolver, sabe? E você vê que a pessoa não domina a área. Daí você já tem que ficar mais atento. Porque numa equipe é o trabalho de todos que precisa ser estabelecido, e daí você precisa resolver esse tipo de situação se for necessário (CP4).

Todavia, cristalizado por teorias e práticas voltadas ao especialista, ao fiscalizador e ao técnico, poucos conseguem enxergar o coordenador como parte integrante 
da equipe docente e organizador do trabalho pedagógico. Conforme Saviani (2008), esse perfil passou a estar intimamente ligado às atribuições administrativas, que já se caracterizam como marcas profundas na representação do coordenador pedagógico e na formação desse profissional. Carneiro e Maciel (2006) apontam sobre a necessidade de o coordenador estar vinculado aos saberes teóricos e práticos, articulando-os de acordo com a realidade de sua atuação. É preciso ampliar os saberes teóricos sem distanciá-los dos conhecimentos práticos.

Com base em Gauthier (1998), os saberes não se apoiam somente na experiência pessoal, ou se reduzem à cientificidade de forma dissociada do espaço real. Essa compreensão contribui para desprofissionalizar o trabalho dos profissionais do ensino. $\mathrm{O}$ autor afirma que o repertório de saberes é um elemento essencial para toda profissão. Identificar e validar um conjunto de saberes específicos tornam-se alicerce para definir o status profissional e identificar conhecimentos próprios que o distinguem de outras profissões. Gauthier (1998) destaca a importância dos saberes das ciências da educação, e isso é essencial ao coordenador pedagógico para exercer sua função na escola.

No relato a seguir, a coordenadora pedagógica aponta os saberes das ciências no trabalho do coordenador pedagógico, ao relatar a importância da filosofia para compreender o ser humano:

Teve aula que era muita teoria, mas aula de didática dava para fazer essa junção com a sala de aula, aula de gestão, até a própria aula de Filosofia, não com a escola, mas como lidar com o ser humano (CP2).

Nesse sentido, os saberes são elementos centrais para todo o processo de profissionalização docente. Tardif (2002) afirma que é a articulação entre a prática e os saberes que faz dos profissionais um grupo social, cuja existência depende, em grande parte, de sua capacidade de dominar, integrar e mobilizar tais saberes.

Ressaltamos a importância de uma formação que ofereça uma bagagem sólida de saberes específicos do trabalho do coordenador pedagógico, que, para tanto, volte seu olhar aos processos educacionais que estão atrelados ao ensino proposto pelo professor e à aprendizagem do aluno. Tal processo deve ocorrer sem se distanciar da realidade escolar e das necessidades da sala de aula. Assim, pontuamos que o curso de Pedagogia se constitui em espaço privilegiado para a formação do coordenador pedagógico, o qual possibilita condições de problematizar a prática pedagógica do professor e de constatar/discutir a lógica ideológica que marca o trabalho na sociedade capitalista (PABIS, 2014). 
A coordenadora pedagógica entrevistada relata a importância da trajetória na escola para a mobilização de saberes na função que exerce:

É fundamental a experiência para o coordenador, porque ele tem que passar pela sala de aula, por vários segmentos e por várias modalidades, educação infantil, EJA, ensino fundamental. Porque, senão, você não tem uma prática certa. Às vezes você fala para o professor: "Ah, o autor fala isso! $\mathrm{E}$ que se você ensinar daquele jeito, dá certo!". Mas será que dá mesmo? (CP5).

Como pondera Gimeno Sacristán (1999), a prática pedagógica, entendida como práxis, é dotada de sentido. Assim, a atuação do professor em sala de aula é um importante espaço para mobilizar saberes, definir estratégias e legitimar práticas pedagógicas para o trabalho docente. Com esse entendimento, Gauthier (1998) elege o saber experiencial como um espaço/tempo privilegiado do profissional da educação, o qual busca mecanismos para sua prática pedagógica e a reproduz de acordo com as necessidades.

O saber adquirido durante a trajetória das coordenadoras pedagógicas na qualidade de professoras, em atuação em sala de aula, é reconhecido pela entrevistada como um componente importante para orientar o trabalho dos professores:

Sem a experiência pedagógica de sala de aula, eu jamais conseguiria orientar as minhas professoras como eu oriento agora. Porque não adianta querer orientar uma coisa que você não sabe fazer (CP6).

Entretanto, para Pinto (2011), não basta ao coordenador pedagógico ter experiência em sala de aula, é preciso obter saberes que envolvem a organização sistêmica da escola, teorias de currículo, políticas públicas na área de educação escolar, avaliação dos processos de ensino e aprendizagem, entre outros saberes que envolvem a atuação do coordenador pedagógico e que ultrapassam os saberes da experiência em sala de aula.

Nesse sentido, destacamos, nos relatos a seguir, os saberes coparticipativos que estão presentes na atuação do coordenador pedagógico. Tratam-se de saberes que envolvem parcerias e experiências adquiridas no espaço escolar por professores, coordenador pedagógico, diretor e todo o coletivo da escola:

Eu fazia parte da equipe dos professores quando fui convidada para assumir como coordenadora pedagógica. Foi complicado em relação às amizades com as outras professoras, pois você não é mais apenas colega das professoras, tive que tomar outra postura. Às vezes eu tenho que dar uma orientação, e, em outras, eu tenho que lembrar algumas normas e as professoras podem não gostar. Então, eu tentei encontrar maneiras de conversar com elas, de me relacionar de forma diferente. Buscando sempre resolver os problemas de maneira coletiva (CP1). 
É preciso saber lidar com as pessoas, para conviver no trabalho com os diferentes pensamentos. No que envolve os conflitos por exemplo, é preciso ter calma, compreender que as pessoas não são todas iguais, isso foi coisas que eu aprendi no curso de Pedagogia e no cotidiano da escola (CP2).

O papel do coordenador pedagógico é complexo, pois não é neutro, considerando que há sempre um posicionamento presente na prática pedagógica que pode realizar tanto a transformação como a confirmação do status quo. Ao refletir sobre o trabalho do coordenador pedagógico no cotidiano da escola, Pabis (2014) aponta que os desafios encontrados estão em desempenhar seu próprio trabalho, com base no repertório de saberes adquiridos ao longo de seu processo formativo.

Tendo em vista que as questões emergentes da dinâmica da escola se tornam preponderantes no trabalho do coordenador pedagógico, na busca por soluções para os problemas momentâneos, esse profissional pode acabar realizando uma atuação desordenada e imediatista. Assim, a velha ideia de "apagar incêndios" torna-se uma referência para o trabalho do coordenador pedagógico, o qual desconsidera a intencionalidade de seu trabalho e os propósitos que envolvem sua atuação no espaço escolar.

Para compreender a condição de trabalho do coordenador pedagógico, é preciso considerar as questões históricas que, para Kuenzer (2006), estão associadas às contradições que envolvem a organização do trabalho na sociedade capitalista. Nesse contexto, permeados por conflitos e determinantes próprios do modo de produção capitalista, a escola e os profissionais que nela atuam se descaracterizam de suas principais finalidades educativas, em favor de ações que produzem resultado em curto prazo.

As precárias condições de funcionamento que a escola apresenta causam um contrassenso no que envolve as possibilidades de ações dos profissionais que atuam nesse espaço, por isso a tendência das contradições entre os saberes adquiridos na formação inicial e as reais possibilidades de atuação no espaço escolar. Desse modo, os profissionais desvinculam-se da sua função, para assumir outras atribuições determinadas por situações que emergem do próprio cotidiano escolar. Assim, é necessário buscar elementos, já no processo formativo do coordenador pedagógico, que permitam compreender os limites do trabalho pedagógico e os determinantes que assolam essa atuação, a fim de ampliar o escopo de possibilidades de intervenção (KUENZER, 2006).

A formação inicial como lócus privilegiado para preparar os futuros profissionais da educação, com sólidos fundamentos teórico-práticos e saberes específicos 
para a prática consciente e autônoma do professor e do coordenador pedagógico, encontra-se desvalorizada nas pesquisas recentes. Gatti (2010) denuncia os cortes de investimento nas universidades públicas, a falta de fiscalização e de normatização dos cursos de formação de professores nas universidades privadas, a falta de equiparação salarial com outros profissionais, entre outros fatores. Considera-se que a desvalorização é ainda reforçada com o entendimento de que qualquer profissional que tenha ensino superior, ou até mesmo ensino médio, pode ser professor.

Assim, a formação inicial é dicotômica, ao considerar o processo de aprendizagem da docência e do coordenador pedagógico, ao mesmo tempo que legitima, também desconsidera práticas cristalizadas. Cabe, dessa forma, à formação inicial exercer o papel de oferecer elementos para o egresso do curso problematizar sobre a prática que exerce. Assim, entra em pauta a exigência de uma formação bem alicerçada em saberes teóricos e práticos, que contemple o rigor científico em consonância com a realidade escolar.

\section{0 trabalho do coordenador pedagógico e seus saberes}

A fim de compreender os saberes que envolvem o trabalho do coordenador pedagógico, fez-se necessário abordar as principais contribuições dos autores que estudam sobre essa temática. Para tanto, destacamos os trabalhos de Gauthier (1998) e Tardif (2002), que discorrem sobre os saberes docentes e a importância destes para o processo de profissionalização do professor, e de André e Vieira (2007), que desenvolvem estudos acerca dos saberes específicos do coordenador pedagógico.

Os esforços de todos os profissionais da educação em incluir a sua formação inicial nos espaços universitários inserem-se na perspectiva de reconhecer o estatuto epistemológico da ciência da educação. De modo contrário a esse movimento, as reformas políticas vêm descaracterizando o profissional da educação como o responsável por uma área específica do conhecimento, reduzindo seus saberes a uma dimensão técnica e tarefeira, que desconsidera sua identidade como cientista e pesquisador.

A desvalorização da formação inicial como espaço de preparação do profissional do ensino e os conceitos preconcebidos do senso comum sobre os saberes que embasam o trabalho do coordenador pedagógico dificultam a constituição de um saber pedagógico. Gauthier (1998) elucida que os saberes encontram-se demarcados por uma espécie de cegueira conceitual, tendo em vista que historicamente se desconsideram a cientificidade e a especificidade dos saberes e que não ponderam a complexidade do trabalho pedagógico. 
Faz-se necessário ultrapassar as concepções demarcadas historicamente que limitam o ofício do professor ao entendimento de que basta conhecer o conteúdo, ter talento, ter bom senso, seguir a intuição, ter experiência ou ter cultura para formalizar os saberes do ensino, seja do professor ou do coordenador pedagógico. Entendemos, como Gauthier (1998), que a prática do ensinar ocorre em uma ampla e abstrusa dimensão. Nesse sentido, os objetivos que orientam a prática pedagógica, os projetos coletivos que estruturam o trabalho realizado na escola, a organização do ambiente físico e social, entre outros aspectos, envolvem a dinâmica do trabalho da escola e obtêm como fim prover melhores condições ao processo de aprendizagem do aluno. Assim, percebe-se como é complexo o trabalho do coordenador pedagógico na organização do espaço escolar.

Nunes (2001) compreende que os saberes são construídos, reconstruídos e mobilizados de acordo com as necessidades profissionais do professor e, no mesmo sentido, do coordenador pedagógico. Portanto, o saber curricular é colocado como imprescindível para o trabalho que o coordenador realiza na escola. No entanto, uma profissional entrevistada afirmou que esse saber foi pouco aprofundado no curso de Pedagogia, o que gerou dificuldades em seu trabalho realizado na escola:

Alguns saberes não foram tão trabalhados no curso e eu considero relevante no meu trabalho na escola, como o currículo que poderia ser mais aprofundado. É preciso um currículo diferenciado para a educação infantil, e isso não foi muito aprofundado no curso. E esse conhecimento me fez falta. Às vezes, na graduação, o acadêmico até pensa que é bom quando o professor não dá muito trabalho, mas depois você percebe que alguns conhecimentos fazem muita falta (CP1).

Domingues (2014) define o coordenador pedagógico como aquele que orienta a organização curricular e o desenvolvimento do currículo. Para tanto, esse profissional precisa obter saberes curriculares para realizar a assistência direta aos professores na elaboração dos planos de ensino, nas práticas de avaliação da aprendizagem, na formação continuada, nas práticas pedagógicas, entre outras atribuições que lhe são pertinentes.

Para Gauthier (1998), o saber curricular é selecionado pela escola a partir dos saberes produzidos cientificamente, para construir um corpus que será ensinado nos programas escolares. Assim, o saber curricular formula-se de maneira externa ao professor, podendo ser produzido pelos funcionários do Estado ou especialistas das diversas disciplinas. $\mathrm{O}$ coordenador pedagógico tem nos saberes curriculares seu lócus de trabalho, tendo em vista que cabe a esse profissional organizar e selecionar, de forma coletiva, o conjunto de conhecimentos pertinentes na formação do aluno. Todos os conhecimentos são dotados de posicionamentos, assim, ao excluir 
ou adotar determinado conhecimento, a escola aguça uma concepção que valoriza em detrimento de outra.

Pensar que o ato de ensinar está atrelado a apenas transmitir um conteúdo é reduzir uma atividade tão complexa quanto o ensino a uma única dimensão. Do mesmo modo, a atuação de coordenar e organizar o trabalho pedagógico não se limita ao saber-fazer - ela possui intencionalidades e pauta-se em saberes pedagógicos definidos. A partir dessa premissa, destacamos que é preciso aprofundar a compreensão sobre os saberes específicos do coordenador pedagógico, para que este não limite sua ação ao talento, à experiência ou à intuição. A formalização do ensino envolve o reconhecimento do coordenador pedagógico como profissional que detém um corpo de saberes particulares do seu trabalho e que, para tanto, necessita de um espaço próprio para concretizá-lo, nesse caso a escola: saberes curriculares, saberes sociais, saberes da prática pedagógica, saberes da experiência (GAUTHIER, 1998; TARDIF, 2002).

Ao tratar dos saberes, Tardif (2002) destaca que o conjunto de processos formativos e de aprendizagem socialmente elaborados destina-se a instruir os membros da sociedade nos saberes sociais. Para isso, cabe aos grupos de educadores que realizam os processos educativos definir suas práticas em relação aos saberes que possuem e transmitem (TARDIF, 2002). Assim, o escopo dos saberes deixa de ser entendido como elemento exclusivo dos docentes e envolve os grupos de educadores. Destacamos, neste trabalho, os saberes que envolvem o coordenador pedagógico como o profissional responsável na organização do trabalho pedagógico. Todavia, é preciso considerar que as ações de formação continuada e orientação que o coordenador pedagógico realiza na escola não devem se limitar aos saberes curriculares, incluindo, assim, no seu trabalho a realidade da escola e sua cultura organizacional (PINTO, 2011). Portanto, ao concretizar suas atribuições, o coordenador pedagógico precisa mobilizar também o saber formador, conforme relatado pelas profissionais a seguir:

A formação continuada eu faço na hora-atividade com a leitura e discussão. Não há tempo disponível, então eu aproveito a hora-atividade. Eu divido o planejamento em três momentos, para fazer o planejamento, para preparar o material que vai ser usado nas aulas e para as discussões (CP1).

$\mathrm{Na}$ escola, é preciso uma formação mediada pela equipe gestora, deveria haver sempre uma formação. Momentos de aprender e refletir sobre a prática sua e do outro, mas não tem tempo (CP2). 
Segundo Nóvoa (1995), a formação continuada possibilita o desenvolvimento pessoal, profissional e organizacional do professor. Assim, a formação continuada é parte integrante de um amplo processo formativo, que abrange aspectos históricos, culturais e sociais do "ser professor". Desse modo, a escola configura-se como lócus de formação do docente, efetivada pelo coordenador pedagógico. Com o entendimento da prática pedagógica como uma ação complexa e intencional, a formação continuada não pode atingir o indivíduo, mas compreende todo o coletivo da escola.

A dificuldade em organizar momentos de formação continuada na escola é retratada pela coordenadora pedagógica da seguinte forma:

Porque é difícil ter reunião pedagógica para trabalhar no coletivo. Na verdade, tem poucos momentos durante o ano letivo, mas, normalmente, é feita já sobre questões do dia a dia. Questões de sala de aula, de disciplina, de trabalho com material diversificado, auxílio aos alunos que têm dificuldade na aprendizagem. Todas essas situações normalmente são realizadas nas reuniões (CP4).

Cabe ao coordenador pedagógico possibilitar que a formação continuada se concretize, a fim de superar a mera aplicação de técnicas e assumir a prática pedagógica como práxis, como fio condutor da formação continuada dos professores. Entretanto, o relato de uma das coordenadoras pedagógicas sobre essa atribuição responsabiliza o professor pelo seu desenvolvimento profissional:

Se o professor não ir atrás, se ele não buscar, não vai conseguir colocar na prática. Então o professor tem que permanecer sempre em formação, sempre buscando, e usar essa formação para colocar em prática aqui na escola. Uma das nossas orientações é que professor tem sempre que reservar um tempo dentro da hora-atividade [...] uma ou duas horas para pesquisa, para leitura de livros mais aprofundados para usar na sua prática (CP1).

A formação continuada é um importante momento para entender a prática pedagógica além do espaço da sala de aula. Compreendemos como limitada a formação continuada que se basta no desenvolvimento da reflexão sobre a própria ação, voltada para uma ação solitária do professor. Cabe ao coordenador pedagógico articular e mobilizar o saber formador, a fim de realizar a formação continuada de forma coletiva e colaborativa.

Ao realizar a formação continuada, valorizam-se os conhecimentos docentes, contribuindo para a construção do coletivo escolar. Nesse sentido, o coordenador pedagógico assume a função de problematizador e mediador na organização da formação continuada no espaço escolar, por meio de referenciais teóricos e de uma postura baseada na cooperação, na alteridade e no diálogo, a qual permite que o professor assuma o processo de construção da sua profissão, como protagonista. 
No que tange ao trabalho em equipe, a coordenadora pedagógica entrevistada reconhece a importância de as ações que se realizam na escola obterem um caráter de coletividade:

Eu acredito que a escola não funciona sem o trabalho em equipe. Até porque hoje eu posso ser coordenadora pedagógica, mas amanhã eu posso voltar para a sala de aula, então as ações não são para o bem individual, é para o coletivo (CP2).

Ao apresentarem os saberes do coordenador pedagógico, André e Vieira (2007) ressaltam que em seu cotidiano, imerso por acontecimentos imprevisíveis, mobilizam-se saberes a cada nova situação. Com base nas autoras, evidenciamos que, no trabalho do coordenador pedagógico, são necessários saberes para realizar ações que envolvem o planejamento da rotina escolar, o acompanhamento do profissional docente e o atendimento de alunos e de pais. Destacamos os saberes que são movimentados pelo coordenador pedagógico na mobilização de pessoas na escola de forma democrática e colaborativa.

A gestão democrática se apresenta a partir dos saberes dialógicos que buscam superar as relações de poder que perpetuam historicamente no espaço escolar. No entanto, a gestão de pessoas, com viés democrático, só acontece quando as ações ultrapassam o âmbito do discurso e se efetivam na escola sustentadas nos princípios dialógicos e na alteridade. O modo como a coordenadora pedagógica mobiliza os saberes no cotidiano da escola denota os sentidos e os significados do partilhar coletivamente. Ou seja, ao privilegiar determinada atuação, o coordenador pedagógico estabelece atitudes de colaboração e partilha. Destarte, consideramos que, ao realizar uma atuação desordenada e/ou autoritária, esse profissional secundariza atos democráticos no espaço pedagógico.

Ao estabelecer as contribuições de alguns autores (GAUTHIER, 1998; TARDIF, 2002), demarcamos a necessidade de analisar os saberes da formação inicial que balizam o trabalho do coordenador pedagógico e as contribuições da formação inicial de licenciatura em Pedagogia. A formação do coordenador pedagógico está atrelada à formação do professor, por isso entendemos que a formação do pedagogo precisa considerar a dimensão teórico-prática da educação. De acordo com a pesquisa realizada por Cruz (2009), os saberes pautados nos fundamentos da educação prevaleceram como principal motriz no início do curso de Pedagogia, o que se modificou ao longo dos anos, a fim de adequar-se às influências da epistemologia da prática.

A ênfase dos saberes apoiados nos fundamentos da educação permitia ao coordenador pedagógico exercer sua profissão com maior segurança em relação às ciên- 
cias da educação. Portanto, o conhecimento desse profissional não ficava restrito ao domínio técnico do conteúdo, que resolve os problemas encontrados na escola com a aplicação de um repertório de conhecimentos e soluções preestabelecidas cientificamente. Entretanto, a ênfase teórica no curso de Pedagogia foi alvo de críticas porque, ao não reconhecer a importância da prática no processo de formação, dificultou a formulação de um saber de cunho pedagógico. Gauthier (1998) aponta que o fracasso em relação à formação de ordem científica do curso contribuiu para desprofissionalizar a atividade docente, ao desconsiderar a importância da pesquisa acadêmica.

Contudo, sustentando-se por um viés estritamente prático, a formação do pedagogo recai no modelo pragmático e utilitário, conforme as necessidades neoliberais. Para Gauthier (1998, p. 27), é como se, ao substituir um modelo formativo por outro, "[...] tivéssemos passado de um ofício sem saberes a saberes sem um ofício". Trata-se de desviar a preocupação de ordem estritamente científica dos saberes, para recair em saberes que desconsideram o contexto real da sala de aula.

Ao conhecer a pluralidade de saberes que envolvem a prática do pedagogo, Cruz (2009) aponta a dificuldade em nomear um saber específico para a pedagogia, considerando os inúmeros conhecimentos que envolvem a formação e a prática pedagógica desse profissional. A autora afirma que o saber da pedagogia deve estar pautado por um entendimento de um saber composto, no qual considera tanto os saberes de base teóricos como também os saberes práticos. Desse modo:

[...] o aprofundamento teórico, pela via das diferentes disciplinas, precisa considerar a educação como prática social e o trabalho pedagógico e docente como a referência primeira da pedagogia e, consequentemente, do seu curso. O tratamento específico dos conhecimentos educacionais, a partir da lógica de cada disciplina e de seu professor, precisa se ligar ao estudo, à reflexão e à pesquisa sobre a educação como prática social, propiciando aos pedagogos em formação fundamentos para teorizar sobre suas práticas e condições para submetê-las à discussão (CRUZ, 2009, p. 13).

Os saberes advêm de diversos contextos e de vários períodos que perpassam a carreira e a história profissional do ensino: as experiências pessoais, a formação inicial, a formação continuada, as atividades docentes, as atividades realizadas na coordenação pedagógica, etc. Assim sendo, os saberes são vastos e diferenciados e, dessa forma, estabelecem-se individualmente e coletivamente, considerando que as ações se configuram como um saber social também subjetivo ao pedagogo. Cabe ressaltar que as ações do coordenador pedagógico não estão desvinculadas das atividades docentes, é necessário compreender os processos de ensino e aprendizagem 
como aspectos basilares para a ação desse profissional na escola, para que a educação seja uma prática social.

Envolvida por uma dimensão complexa e ampla, a prática pedagógica não é uma ação mecânica, o coordenador pedagógico e o professor exercem influências que não permitem neutralidades políticas e epistemológicas em suas ações. Dessa forma, a escola é permeada por concepções sociais, políticas, históricas, econômicas e culturais, que estão presentes nas características singulares de cada ação educativa, desde o planejamento até o desenvolvimento das práticas pedagógicas. As ações são cercadas de saberes específicos que caracterizam as práticas com conhecimentos próprios, conforme suas exigências e sua área de atuação.

A ação do coordenador pedagógico é constituída por vários saberes que, de acordo com Gauthier (1998), englobam conhecimentos, competências, habilidades e atitudes. A formação é um aspecto complexo da educação, que envolve uma gama de conhecimentos que estão além de técnicas e de soluções prontas. Dessa forma, é preciso considerar os saberes que os professores e os pedagogos já possuem ao adentrar no curso de formação inicial e os saberes que serão construídos no processo formativo.

Tardif (2002) corrobora ao destacar que o saber não é algo indefinido ou que flutua no espaço; ao contrário, o saber está relacionado a uma pessoa e à sua identidade. Para compreender os saberes, é necessário estudá-los, relacionando-os com os elementos constitutivos do trabalho docente (TARDIF, 2002). Nesse mesmo sentido, Gauthier (1998) pontua que os saberes próprios do ensino não são identificados no vazio, é preciso levar em consideração o contexto real em que o ensino se realiza, caso contrário temos o risco de formalizar um ofício que não existe.

Para Cruz (2009), o saber é composto, sendo teórico e prático, que reúne traços conceituais de diferentes campos, mas, quando voltado propositivamente a determinado contexto, transforma-se em um novo saber - não mais vinculado à sua fonte de origem, mas como expressão de um novo saber de base teórico-prática.

$\mathrm{Na}$ busca de consolidar um repertório de conhecimentos específicos do ensino, visando garantir a legitimidade da profissão e definir o status profissional dos professores, Gauthier (1998) apresenta um conjunto de saberes docentes, a fim de perceber de que modo os professores os mobilizam, são eles: saber disciplinar, saber das ciências da educação, saber da tradição pedagógica, saber experiencial, saber da ação pedagógica.

Ainda de acordo com Gauthier (1998), o saber disciplinar é produto das pesquisas e corresponde a diversas áreas do conhecimento. Esse saber não é produzido 
pelo professor, mas, sim, pelos cientistas, os quais deflagram uma dualidade entre o espaço de produção de pesquisa e o ensino. Entretanto, ao mobilizar o conhecimento, o professor extrai o saber produzido pelos pesquisadores, para transformá-los em conhecimentos relevantes em sala de aula. Assim, o ato de ensinar exige um conhecimento. Como pondera Tardif (2002), “[...] um professor é, antes de tudo, alguém que sabe alguma coisa e cuja função consiste em transmitir esse saber a outros”. Dessa forma, o domínio do conteúdo torna-se necessário para compreender determinados conceitos.

Do mesmo modo, para Gauthier (1998), o ato de ensinar exige um conhecimento de determinado conteúdo, levando em consideração que não há condições de ensinar algo sem conhecimentos peculiares de determinada área. Nesse sentido, o saber disciplinar possibilita ao professor superar o saber-fazer e obter domínio dos conteúdos que mobiliza em sala de aula. Sem conteúdo, o ensino torna-se vazio e cercado de senso comum. Por isso, "[...] os conteúdos são fundamentais, sem conteúdos relevantes, conteúdos significativos, a aprendizagem deixa de existir, ela transforma-se num arremedo, ela transforma-se numa farsa" (SAVIANI, 2008, p. 45). Assim, o saber disciplinar não se realiza com base no entendimento do profissional do ensino como técnico, mas em uma prática consciente que contribui para a emancipação dos sujeitos, que passam a obter conhecimentos de conteúdos historicamente sistematizados. Gauthier (1998) coloca que o conteúdo do saber da ação, ou seja, o saber-fazer, não é suficiente para atender a complexidade da ação pedagógica, seja do professor ou do coordenador pedagógico.

Pinto (2011) destaca que a escola realiza inúmeras práticas educativas, mas que não estão ligadas exclusivamente à sala de aula; elas vão além do trabalho entre o professor e o aluno. Então, a sala de aula não é um espaço isolado da escola; ela é cercada por outros elementos e profissionais que, mesmo fora desse espaço, têm suas contribuições, obtendo como fim o processo de aprendizagem dos alunos. Assim, entende-se o coordenador pedagógico como profissional que atua tanto no espaço de sala de aula, na qual realiza o suporte pedagógico para o trabalho docente, como na organização do trabalho pedagógico, articulando os espaços coletivos de formação contínua do professor, mobilizando a construção e a implementação coletivas do projeto político-pedagógico, entre outras atribuições.

Ao considerar que o coordenador pedagógico realiza ações tanto em sala de aula, de forma indireta, como no espaço escolar, é necessário compreender os saberes disciplinares que são mobilizados em sala de aula e como se encontram organizados na estrutura da escola em um escopo mais amplo. Em relação à atuação 
do coordenador pedagógico na educação infantil e no ensino fundamental, compreender os conteúdos para melhor orientar o professor torna-se imprescindível, sobretudo com os professores iniciantes.

O saber das ciências da educação é responsável por caracterizar o coordenador pedagógico, já que esse saber se adquire pelo próprio profissional do ensino durante a sua formação ou em sua trajetória na escola. Conforme Gauthier (1998), é um saber profissional específico, que nem sempre está ligado à ação pedagógica, mas se refere à maneira de o professor existir profissionalmente. Em suma, este saber compreende as noções do coordenador relativas ao sistema escolar, como o projeto político-pedagógico, o conselho escolar, a Associação de Pais, Mestres e Funcionários, entre outras noções específicas do espaço escolar e do seu trabalho.

A tradição pedagógica refere-se ao modelo de escola instaurado no século XVII, que, conforme pontua Gauthier (1998), deixa de ocorrer no singular, no qual o professor atende o aluno individualmente, passando a realizar-se de maneira simultânea. Esse modelo de escola cristalizou uma tradição pedagógica que remonta às ações desenvolvidas na escola durante períodos anteriores e encontram-se presentes até os dias atuais. Nesse sentido, a escola não é um espaço neutro, e muito menos seus agentes o são, pois desenvolvem as atividades escolares arraigados e permeados por um contexto cultural e histórico.

As atitudes e os automatismos inerentes às profissões do professor e do coordenador pedagógico não dizem respeito somente a gestos e atos concretos observáveis, mas, além disso, se realizam por percepções e emoções. Assim, o habitus constitui-se por meio da reprodução de percepções, de pensamentos e de ações (BOURDIEU, 2008). Os esquemas de percepções, ações e emoções reproduzem-se na escola na relação entre o individual e o coletivo. Eles estão presentes desde o currículo até as práticas cotidianas, muitas vezes sem a devida compreensão dos significados que nutrem a escola e seus agentes com um sistema de habitus que perpassa e desenvolve uma cultura escolar.

O saber experiencial compõe os saberes advindos da prática do profissional da educação e denota um campo significativo para a produção de um repertório de saberes da experiência e produzido pelo próprio professor (GAUTHIER, 1998). Do mesmo modo, Tardif (2002) seleciona os saberes da experiência como conjunto de saberes utilizados, adquiridos e necessários no espaço da prática da profissão docente, que são elaborados pelo próprio professor. O autor aponta que é no cotidiano do professor que os saberes experienciais se consolidam e se estabelecem como núcleo vital do saber docente, que são, acima de tudo, de ordem pessoal. 
O saber da ação pedagógica é legitimado pela pesquisa. Desse modo, é o saber experiencial dos professores que se torna público, para alvo de avaliação, reprodução e comparação. Entretanto, Gauthier (1998) denuncia a dificuldade de o saber fazer-se presente no reservatório de saberes do professor, tendo em vista que o docente se encontra isolado nas práticas em sala de aula e poucas vezes torna públicas as suas experiências particulares. Assim, Gauthier (1998, p. 34) discute sobre a importância do saber da ação pedagógica para "[...] contribuir enormemente para o aperfeiçoamento da prática docente", ao considerar que esse saber constitui um elemento da profissionalização docente, já que favorece a realização de comprovação científica sobre o saber da ação pedagógica.

As experiências tanto profissionais como pessoais interferem na consolidação dos saberes do coordenador pedagógico, que os desenvolve em relação às suas práticas pedagógicas exercidas na escola. Sobre a temporalidade dos saberes, Tardif (2002) afirma que estes sofrem modificações ao longo do tempo, de modo que não são imutáveis e homogêneos. No espaço da escola, o coordenador pedagógico elege, modifica e recompõe seus saberes de acordo com as necessidades do seu trabalho.

Pontuamos que a profissionalização do coordenador pedagógico não está direta e unicamente associada à constituição de saberes. Gauthier (1998) aponta que os saberes se caracterizam como elementos imprescindíveis para estabelecer uma legitimidade ao profissional, mas também é necessário que “[...] se estabeleça uma distinção nítida entre a produção e a utilização dos conhecimentos" (GAUTHIER, 1998, p. 286). Para tanto, compreendemos que a profissionalização, também, está relacionada às dimensões políticas do reconhecimento da especificidade do seu trabalho. Cabe, então, à formação inicial a preparação do profissional do ensino com o real reconhecimento do seu trabalho, para que não recaia somente no saber-fazer, mas nas amplas dimensões históricas, econômicas, culturais, políticas e epistemológicas da profissão.

\section{Considerações finais}

Sendo a universidade, no curso de Pedagogia, o lócus da formação do coordenador pedagógico, esta precisa dotar-se de saberes que permitam ao profissional da educação que se forma "[...] construir uma competência profissional que o ajude a intervir frente às demandas de seu trabalho, em especial, na condução dos processos de formação do docente sistematizadas na escola” (DOMINGUES, 2014, p. 35). Para além desses aspectos, a formação inicial é uma possibilidade de compreender 
as contradições que envolvem a escola e o trabalho do coordenador pedagógico. Porém, muitas vezes, o trabalho do coordenador pedagógico se envolve em uma atuação fragmentada e alienada.

A atuação dispersa do coordenador pedagógico, que desconsidera os saberes específicos do seu trabalho, é resultado das contradições presentes na organização do trabalho na sociedade capitalista. Kuenzer (2006) ressalta que essa atuação é decorrente da fragmentação do trabalho pedagógico, que inclui a formação inicial, em um espaço que divide o pensamento prático e o teórico. Nesse sentido, a fragmentação curricular na formação desse profissional divide o conhecimento em áreas e disciplinas trabalhadas de forma isolada, que supõem uma autonomia da prática social impossível de acontecer. Analisar a formação inicial do coordenador pedagógico torna-se uma tarefa árdua quando se consideram as contradições presentes no processo formativo e, consequentemente, no trabalho desse profissional.

Por meio da análise empreendida nesta pesquisa, pontuamos algumas considerações sobre as contribuições do curso de Pedagogia na construção dos saberes necessários para a prática do coordenador pedagógico. Entretanto, ressaltamos que estas considerações são partes de um inconcluso processo de problematizar a formação e o trabalho do coordenador pedagógico, pois esta é uma tarefa complexa, que, segundo Gauthier (1998), envolve saberes da experiência, saberes da tradição pedagógica, saberes das ciências da educação, saberes curriculares e saberes disciplinares.

Consideramos a necessidade de um curso de formação inicial consistente teoricamente, que seja desenvolvido pela articulação da teoria com a prática e que promova mecanismos para tratar e aprofundar os saberes necessários ao trabalho pedagógico do coordenador. Ao assumir a função na escola, o coordenador pedagógico mais se aproxima de um multitarefeiro e deixa de realizar suas principais atribuições, entre elas a organização e mobilização da construção coletiva do projeto político-pedagógico e a formação continuada dos docentes, com ações que marginalizam seus saberes específicos. Nesta pesquisa, apontamos a dificuldade dos coordenadores em estabelecer espaço e tempo destinados para a formação contínua dos profissionais do ensino.

Embora se reconheça a formação inicial como um importante espaço de construção dos saberes do coordenador pedagógico, evidenciamos que a indefinição nas atribuições desse profissional se torna mais agravante quando se consideram os modelos assumidos no processo formativo. Conforme analisado, o modelo de formação do especialista e do professor, ora pesquisador, ora docente e ora gestor, resulta em uma compreensão histórica de fragmentação, tanto no perfil como no trabalho 
que assume esse profissional. A amplitude da formação do coordenador pedagógico desafia as possibilidades de educar um mesmo profissional para diversas funções que, apesar de correlatas, possuem especificidades próprias.

$\mathrm{O}$ curso de Pedagogia apresenta um aspecto abrangente, pois insere várias temáticas e disciplinas que caracterizam um "inchaço curricular", apesar de considerar a importância das temáticas apresentadas. Trata-se de uma formação voltada mais à docência, que, em decorrência, secundariza saberes específicos da formação do coordenador pedagógico. Logo, a formação com um aspecto amplo concentra disciplinas na formação docente, o que resulta, ao final do curso, em um profissional que não reconhece quem são: o coordenador pedagógico, o gestor e o docente.

\section{Notas}

1 Se faz presente na Grécia Antiga o termo paidéia, que se referia à formação do homem para viver em sociedade. A paidéia estava fundamentada nos conhecimentos filosóficos e culturais, abordando aspectos teóricos do ensino (SAVIANI, 2008).

2 Ao destacar tais transformações, apontamos: a crise do Estado de bem-estar social; o aumento das taxas de inflação; o modelo de organização do trabalho com base no taylorismo-fordismo; o questionamento das noções de razão, de verdade, de progresso, de emancipação, de igualdade; as críticas às metanarrativas, às noções de estrutura e de totalidade; a descrença no sujeito histórico; entre outras (BOURDIEU, 2008).

3 Vieira (2009) destaca as propostas de reformas do período da Primeira República (1889-1930): Reforma Benjamin Constant (1890-1891), Reforma Epitácio Pessoa (1901), Reforma Rivadávia Corrêa (1911), Reforma Carlos Maximiliano (1915) e Reforma João Luiz Alves (1925).

\section{Referências}

ANDRÉ, M. E. D. A.; VIEIRA, M. M. da S. O coordenador pedagógico e a questão dos saberes. In: ALMEIDA, L. R.; PLACCO, V. M. N. de S. (org.). O coordenador pedagógico e questões da contemporaneidade. 2. ed. São Paulo: Loyola, 2007. p. 11-24.

BARDIN, L. Análise de conteúdo. Lisboa: Edições 70, 1977.

BOURDIEU, P. Para uma sociologia da ciência. Lisboa: Edições 70, 2008.

BRASIL. Lei no 9.394, de 20 de dezembro de 1996. Diário Oficial [da] República Federativa do Brasil, Poder Legislativo, Brasília, DF, 23 dez. 1996. Seção 1, n. 248, p. 27833-27841.

CARNEIRO, I. M. S. P.; MACIEL, M. J. C. Pedagogia e pedagogos em diferentes espaços: interdisciplinaridade e competências pedagógicas. In: ENCONTRO NACIONAL DE DIDÁTICA E PRÁTICA DE ENSINO - ENDIPE, 13, 2006, Pernambuco, Recife. Anais... Recife: Universidade Federal de Pernambuco, 2006. p. 210-231.

CRUZ, G. B. 70 anos do curso de Pedagogia no Brasil: uma análise a partir da visão de dezessete pedagogos primordiais. Educação \& Sociedade, Campinas, v. 30, n. 109, p. 1187-1205, set./ dez. 2009. 
DOMINGUES, I. O coordenador pedagógico e a formação continuada do docente na escola. São Paulo: Cortez, 2014.

FRANCO, Maria Amélia Santoro. A pedagogia como ciência da educação. Campinas: Papirus, 2003.

GATTI, B. Formação de professores no Brasil: características e problemas. Educação \& Sociedade, Campinas, v. 31, n. 113, p. 1355-1379, out./dez. 2010.

GAUTHIER, C. Por uma teoria da pedagogia. Pesquisas contemporâneas sobre o saber docente. Ijuí: Unijuí, 1998.

GIMENO SACRISTÁN, J. Poderes instáveis em educação. Porto Alegre: ArtMed, 1999.

KUENZER, A. Z. As diretrizes curriculares para o curso de Pedagogia: uma expressão da epistemologia da prática. In: ENCONTRO NACIONAL DE DIDÁTICA E PRÁTICA DE ENSINO ENDIPE, 13, 2006, Pernambuco, Recife. Anais... Recife: Universidade Federal de Pernambuco, 2006. p. 185-212.

LIBÂNEO, J. C. Pedagogia e pedagogos: inquietações e buscas. Revista Educar, Curitiba, n. 17, p. 153-176, 2001.

NÓVOA, A. Formação de professores e profissão docente. In: NÓVOA, A. (coord.). Os professores e a sua formação. Lisboa: Dom Quixote, 1995. p. 13-33.

NUNES, C. M. F. Saberes docentes e formação de professores: um breve panorama da pesquisa brasileira. Educação e Sociedade, Campinas, n. 7, p. 27-42, abr. 2001.

PABIS, N. O trabalho do pedagogo na escola pública do Paraná. 2014. 197 f. Tese (Doutorado em Educação) - Universidade Tuiuti, Curitiba, 2014.

PIMENTA, S. G. (org.). Saberes pedagógicos e atividade docente. São Paulo: Cortez, 1999.

PINTO, U. A. Pedagogia escolar: coordenação pedagógica e gestão educacional. São Paulo: Cortez, 2011.

PLAISANCE, E.; VERGNAUD, G. Les sciences de l'éducation. Paris: La Découvert, 1993.

SAVIANI, D. História das ideias pedagógicas no Brasil. Campinas: Autores Associados, 2008.

TARDIF, M. Saberes docentes e formação profissional. Petrópolis: Vozes, 2002.

VÁZQUEZ, A. S. Filosofia da práxis. Rio de Janeiro: Paz e Terra Ltda., 1968.

VIEIRA, S. L. Reformas educativas no Brasil: uma aproximação histórica. In: TERCER CONGRESO NACIONAL Y SEGUNDO ENCUENTRO INTERNACIONAL DE ESTUDIOS COMPARADOS EN EDUCACIÓN, Ceará. Anais... Ceará: Fortaleza, 2009. Disponível em: http:// docslide.com.br/documents/reformas-educativas-no-brasil-uma aproximacao-historica.html. Acesso em: 25 jul. 2015.

ZAVAGLIA, T. Critérios de validade cientifica nas ciências humanas. Educação, Santa Maria, v. 33, n. 3, p. 469-480, set./dez. 2008. 